\title{
The EPMA Matrix Correction: All Elements Must Be Present for Accuracy: Four Examples with B, C, $O$ and $F$
}

\author{
John Fournelle ${ }^{1}$, Aurélien Moy ${ }^{2}$, William Nachlas ${ }^{1}$ and John Donovan ${ }^{1}$ \\ ${ }^{1}$ Department of Geoscience, University of Wisconsin - Madison, Madison, Wisconsin, United States, \\ ${ }^{2}$ University of Oregon, Eugene, Oregon, United States
}

Historically, many EPMA labs have neglected to measure all of the elements present in some samples, either because it was impossible or difficult to acquire low energy/long wavelength X-ray lines, or because they could be assumed to be present and correctly accounted for by stoichiometric apportionment and post-processing outside the matrix correction. With the availability of layered synthetic diffractors since the late 1980s, it became possible, with attention to detail, to quantify B, C, N, O and F [1]. It has been 24 years since Tingle et al [2] pointed out the importance of including "missing" oxygen in EPMA measurements, and there is the need to remind our community of this not insignificant aspect of EPMA, especially as new generations of microanalysts learn the technique. We present four examples where the inclusion of ALL elements is essential for accurate and complete correctionof matrix effects: carbonate minerals, hydrous minerals, hydrous carbonates, and borate minerals.

Common carbonate minerals are calcite, dolomite, and ankerite. Typically, one would measure Ca, $\mathrm{Mg}, \mathrm{Fe}, \mathrm{Mn}$ and possibly $\mathrm{Sr}$ and $\mathrm{Ba}$. These elements in carbonate minerals have well-defined oxygen stoichiometry, and when the matrix correction includes that, the results total around $49 \mathrm{wt} \%$. In the past, it has been common to put these values into a spreadsheet, generate atomic values and generate a value for $\mathrm{CO} 2$. There are two problems with this: the low analytical total does not directly inform the analyst whether there is an analytical problem, and the cation numbers are in error. One example: $\mathrm{Mg}$ is low by $6 \%$, Ca by $4 \%$ and $\mathrm{Fe}$ by $3 \%$.

Use of Probe for EPMA analytical software enables direct inclusion of the $\mathrm{CO}_{2}$ into the matrix correction based upon the stoichiometric relationship of (total cations) : carbon : oxygen of 1:1:3. We show that microanalysts are able to implement this correction by post-processing experimental data in the free CALCZAF software program. This approach offers an excellent QC test: does the recast analytical total approach $100 \mathrm{wt} \%$ and does the mineral formula on 3 oxygens approach 5.000 ?

Another situation where it has been common to ignore "difficult/impossible" elements is the of borosilicatetourmaline minerals (e.g., schorl, dravite, elbaite). Published EPMA compositions typically show analytical totals of $\sim 82-85 \mathrm{wt} \%$. Residual components include a significant amount of $\mathrm{B}_{2} \mathrm{O}_{3}(\sim 10-$ $11 \mathrm{wt} \%$ ), water $(\mathrm{OH})$, and $\mathrm{F}$ (and $\mathrm{Li})$. Our analytical routine involves: two beam conditions $(7 \mathrm{kV}$ for $\mathrm{B}$, $\mathrm{O}$ and $\mathrm{F}$, and $15 \mathrm{kV}$ for the remaining elements), mounting the standards together with the unknowns, carbon coating standards and unknowns simultaneously, and using the correct MACs (Bastin or Pouchou) for the "light elements" $(Z<11)$. The EPMA measurements for B using this routine agree closely with results of other techniques [3[. Measurement of $\mathrm{O}$ is very useful, particularly where there is the potential presence of hydrogen (as $\mathrm{OH}$ ), as this measurement provides a means to estimate this "missing element" and include it into the matrix correction. (Where $\mathrm{Li}$ is measured by another technique, its value may be also included into the matrix correction.)

When $\mathrm{B}, \mathrm{O}$, and $\mathrm{F}$ are not included in the matrix correction, there are errors, albeit generally small: $\mathrm{Si}$ (used for normalizing mineral formulas) is $1 \%$ high, $\mathrm{Al}$ is $1 \%$ low (except in elbaite, $3 \%$ low), both $\mathrm{Fe}$ 
and $\mathrm{Mg}$ are $1 \%$ low, and $\mathrm{Na} 2-3 \%$ low. When $\mathrm{B}, \mathrm{O}$ and $\mathrm{F}$ are measured, the analytical totals are in the 98.5-99 wt\% range (Table 1).

A third example is apophyllite, $\mathrm{KCa}_{4} \mathrm{Si}_{8} \mathrm{O}_{20}(\mathrm{~F}, \mathrm{OH})-8 \mathrm{H}_{2} \mathrm{O}$, where measurement of the cations and stoichiometric apportionment of $\mathrm{O}$ yields an analytical total of $82 \mathrm{wt} \%$. Explicit measurement of $\mathrm{O}$ and incorporation of it as $\mathrm{H}_{2} \mathrm{O}$ yields a $99.6 \mathrm{wt} \%$ total (Table 2).

As an example of hydrocarbonates, we tested this approach with analysis of hydromagnesite, $\mathrm{Mg}_{5}\left(\mathrm{CO}_{3}\right)_{4}(\mathrm{OH})_{2}-4 \mathrm{H}_{2} \mathrm{O}$. Here, both $\mathrm{C}$ and $\mathrm{O}$ must be directly measured. Application of Ir coating to the standards and sample aids in the determination of $\mathrm{Mg}, \mathrm{C}$ and $\mathrm{O}$; after $\mathrm{O}$ was apportioned stoichiometrically to $\mathrm{Mg}$ and $\mathrm{C}$, there was $17 \mathrm{wt} \%$ residual and a low total of $95.9 \mathrm{wt} \%$. If the "excess" $\mathrm{O}$ was defined as $\mathrm{H} 2 \mathrm{O}$ (19.8 wt\%), the resulting total was $99.74 \mathrm{wt} \%$.

Results of this work show that incorporation of all elements present in a material results in a more accurate determination of chemical composition with EPMA, and the use of software programs for postprocessing of matrix corrections enables complete characterization of challenging materials [4].

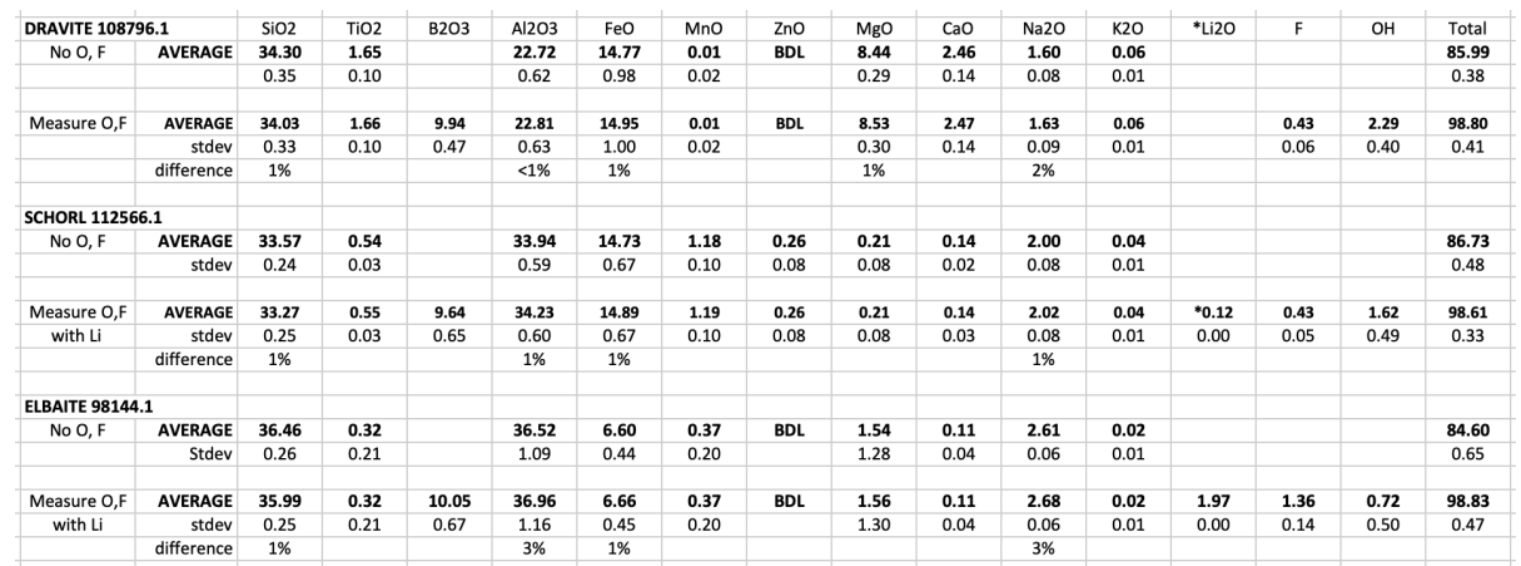

Figure 1. Table 1

\begin{tabular}{r|c|c|c|c|c|c|c|c}
\hline & $\mathrm{Si}$ & $\mathrm{Al}$ & $\mathrm{Ca}$ & $\mathrm{K}$ & $\mathrm{F}$ & $\mathrm{O}$ & "H" & Total \\
\hline O by stoich & 24.05 & 0.13 & 17.01 & 3.81 & 2.44 & 34.11 & & 81.67 \\
\hline O measured & 24.76 & 0.14 & 17.37 & 3.90 & 2.51 & 49.00 & 1.76 & 99.57 \\
\hline difference & $3 \%$ & $3 \%$ & $2 \%$ & $2 \%$ & $3 \%$ & & & \\
\hline
\end{tabular}

Figure 2. Table 2

\section{References}

[1] Nash, 1992, American Mineralogist, 77, 453.

[2] Tingle, Neuhoff, Jones and Donovan, 1996, GSA Abstract, 28 (6), 212.

[3] Dyar et al., 2001, Geostandards Newsletter, 25 (2), 1.

[4] Support for this research came from the National Science Foundation: EAR-1337156 (JHF), EAR1554269 (JHF) and EAR-1849386 (JHF). 